

2011-WP-19

August 2011

\title{
Underwriting in Property-Casualty Insurance Markets: Regulation, Risk and Volatility
}

Ronnie J. Phillips and David Nickerson

Abstract: We offer a novel explanation of underwriting volatility in propertyliability insurance markets in terms of private uncertainty over public regulatory policy. Underwriting involving random losses to policyholders is one source of risk to the equity value of insurance firms. Solvency regulations, however, pose a second source of risk to equity value when the implementation of such regulations randomly affects the return to underwriting but exhibits imperfect correlation with market conditions over time. Using a differential game in a standard no-arbitrage environment to model interaction between these two sources of risk, we derive the valuation equation for property-liability underwriting inclusive of the respective bestreply underwriting strategy of a representative insurance firm and the implementation strategy of a representative regulator. Owing to the conflicting effects of these strategies on firm equity, regulations adopted to reduce the solvency risk of insurers can, paradoxically, increase underwriting volatility in an otherwise efficient insurance market. Under certain parametric conditions, we also show that, even in the presence of complete financial markets, a subgame perfect Nash equilibrium of this game can exhibit a limit cycle in the value of underwriting which mirrors empirical evidence on the presence of cycles in property-liability insurance markets.

About the Authors: Ronnie J. Phillips is a Senior Fellow at Networks Financial Institute. He has retired as a Professor of Economics at Colorado State University. Most recently he was a Scholar in Residence at the Ewing Marion Kauffman Foundation and a Visiting Research Fellow at the American Institute for Economic Research. Previously, he has been a Visiting Scholar at the Federal Deposit Insurance Corporation, the Comptroller of the Currency, and at the Jerome Levy Economics Institute of Bard College. He is a past president of the Association for Evolutionary Economics. His publications on financial system issues have appeared in books, academic journals, newspapers, magazines and public policy briefs. Philips holds a B.A. from the University of Oklahoma and a Ph.D. from The University of Texas at Austin. David Nickerson is Professor and the inaugural Marshall Bennett Chair in Finance, Economics and Real Estate at Roosevelt University, where he joined the faculty in 2005, after being Principal Economist and Deputy Chief Economist at Freddie Mac; senior financial economist at the U.S. Treasury Office of Thrift Supervision; an advisor on insurance economics to the National Economic Council; a professor of economics and finance at Colorado State 
University, the University of British Columbia, the University of Canterbury and American University. He has also been an economic advisor to the Institute of Economics in Hanoi and to the Jiangsu and Sichuan research institutes (PRC); an Erskine Fellow at Victoria University of Wellington (NZ); a Research Fellow at the Federal Reserve Banks of Kansas City and St. Louis; and a consultant to the Federal Reserve System, the U.S. Treasury, and the Center for Naval Analyses. He conducts research in the areas real and financial asset valuation; insurance economics and the economics of catastrophes, and financial economics and public policy. His principal areas of research include financial economics and public policy, financial intermediation, real and financial asset valuation; insurance economics and the economics of catastrophes. He has published over forty research papers in academic and practitioner journals and two books on financial markets in developing economies; presented his research at numerous seminars and conferences; and has served on the editorial board s of three academic journals and as a referee for the National Science Foundation, the National Academy of Sciences, the Social Science and Humanities Research Council (Canada) and numerous academic journals. Dr. Nickerson holds a Ph.D. in economics from Northwestern University (1982).

Keywords: Property Casualty Insurance, Cycles, Regulatory Risk. JEL Classification: D82, D92, G22, G28, K13, L51.

The authors thank Tom Husted, Leo Petrosjan, Jack Tatom, Galina Timofeeva and seminar participants at the American Risk and Insurance Association Annual Meetings, the Asia-Pacific Finance Association Meetings, the Congressional Budget Office, Freddie Mac, and Saint-Petersburg State University for helpful comments. The views expressed are those of the individual authors and do not necessarily reflect official positions of Networks Financial Institute. Any errors or omissions are the responsibility of the authors. Please address questions regarding content to Ronnie J. Phillips at rphillipcsu@aol.com.

NFI working papers and other publications are available on NFI's website (www.networksfinancialinstitute.org). Click "Thought Leadership" and then "Publications/Papers." 


\section{Introduction}

The property-liability insurance industry has traditionally exhibited recurrent cycles in the pricing and volume of insurance coverage in both the domestic and foreign economies. Owing to its implications for existing theories of insurance pricing and for the efficiency of private insurance markets, it is a significant concern of businessmen, economists and policymakers. Interpretation of the causes of this cycle is, in particular, fundamental to both the rationale and design of public insurance regulations.

This paper offers a novel explanation of the cycle in property-liability insurance markets. Based upon the traditional premises of financial theory, this explanation contrasts sharply with the popular belief that such markets are inefficient and with extant theoretical rationales of insurance cycles based upon various forms of market failure. Our explanation is based upon the interaction between uncertainty over the evolution of the costs of covered losses to insurers in the absence of regulation, which we term exposure risk and regulatory risk which we define as the uncertainty over future regulatory actions affecting the ability of insurers to offer optimal insurance contracts, which fully incorporate current expectations of the magnitude of random future losses, and the demand by potential policyholders for such contracts.

Analogous to risks to asset values in more general financial markets, exposure risk is associated with the liability assumed by the insurer through underwriting coverage of random future losses as well as the related potential costs posed to insurers by stochastic market demand and underwriting costs. Regulatory risk is associated with random regulatory actions intended to influence the response of insurers to changes in the excess demand for insurance. Ironically, these actions, which arise from the (stated) preference of policymakers for stability in property-liability insurance markets, have the potential to induce substantial instability, reflected in the cyclic volatility of pricing and available coverage, in these same markets.

The paper is organized as follows. Section II provides an explanation of the underwriting cycle and uses the case of the Katrina disaster as an example of the cycle in the real world. Our model of underwriting and the valuation equation for the representative insurance firm are developed in Section III. A solution for the value of the firm and a general characterization of market equilibrium appear in Section IV. Plausible parametric conditions under which an underwriting cycle will occur are derived in Section V. Section VI discusses the implications of our analysis for the economic efficiency of the property-liability insurance markets and for the effects on such efficiency of public policy and regulations in such markets. Concluding remarks appear in the final section.

\section{The Insurance Cycle}

\section{II.1 Insurance Market Structure}

The purpose of liability insurance is to cover individuals and corporations in the event of an unforeseen accident that imposes costs on the insured party. Insurance companies charge premiums that are expected to equal or exceed the costs of these accidents. In the U.S., the largest liability insurance markets are for automobiles and workers' compensation (Winter 1994, p. 117).

A major topic in liability insurance is the existence of cycles of profitability for the insurance companies. This cycle is measured by the ratio of claims (losses) to premiums. ${ }^{1}$ This cycle is evident from Figure 1, which plots the net premiums written for the property and casualty industry over the period 1939-2010 (Baker 2010).

1 Although the loss ratio is the standard measure of current return in actual property-casualty insurance markets as well as in virtually all actuarial and insurance economics research, it is best regarded as an empirical proxy for such a return. Winter (1994) argues that a proper measure of return should be the ratio of the present-value of the expected claims to 


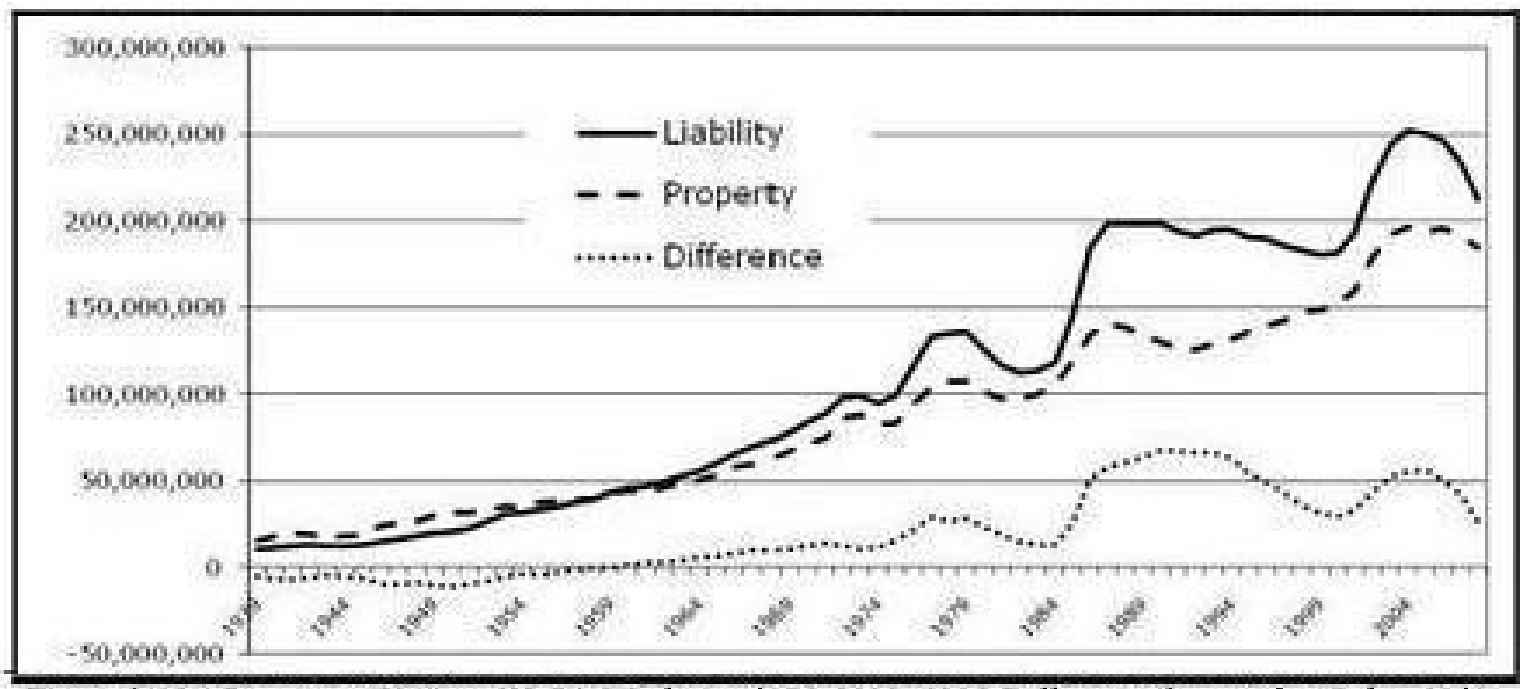

Figure 1: Net Premuiums W/ritten, US P\&C Industry 1939-2008 2008 Dollar s (un thousands) (Baker 2010)

The cycle becomes more apparent in Figure 2. The first differences in the economic loss ratio follow a second-order autoregressive process which means that the predicted value for the ratio in any year $t$, given its history up to that year, depends on the realized values for the previous two years.

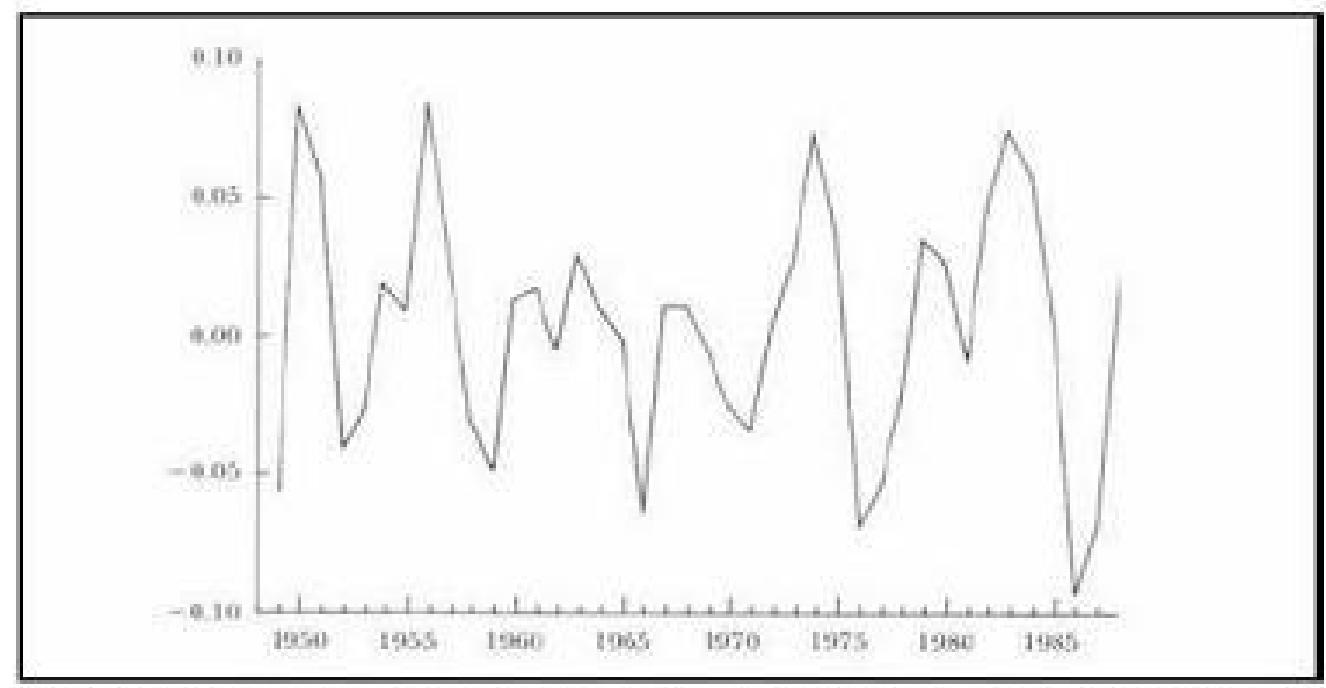

Figure 2: First Differences in Economic Los Ratio. Property-Liability Insurance, 1948-1988, (Winter 1994)

This implies a dampening cycle with a period of 8.6 years (Winter 1994, p. 118). The useful explanation is that competition drives prices down to the point where losses deplete industry reserves. Loss ratios in the global reinsurance market and for firms participating in both primary and reinsurance markets also exhibit similar cycles.

How can these recurrent fluctuations be consistent with efficient financial markets? A plausible explanation of the cycle must recognize periods of rapid increases in premium revenues, the rationing of insurance for some

the premiums collected. By estimating the maturity structure for actual cash flows, the term structure of discount rates appropriate for property-casualty risk, and taking the accounting reserve as a proxy for expected non-discounted losses, it would be theoretically possible to calculate an "economic loss ratio," (Winter 1994, p. 117). Valuation based on this ratio, however, is not only empirically impractical, since available time-series data for property-casualty insurance markets is ased solely on usage of the traditional form of the loss ratio, but is also superceded by the contingent claims method used in more modern research, including Embrechts (2009), Melnikov (2004), Jones and Nickerson (1994) and the current paper. 
buyers, and the large number of risks that are left uncovered. Prior explanations of the cycle all rely on one or more forms of market failure in property-casualty insurance. Winter (1994), for example, studies a model that incorporates the assumptions of $(i)$ imperfect competion through a mix or organizational forms supplying the market and (ii) asymmetric information among investors, causing new capital to enter the market more quickly during a cyclic downturn or "tight" market. (Winter 1994, pp. 119-120). Below we discuss this cycle in casualty-liability insurance markets, using coverge of catastrophic loss as an example.

\section{II.2 Catastrophic Insurance}

The basic principles of insurance dictate that the current value of premiums in a competitive market should equal the current value of expected payout. This requires an underlying probability distribution for the insured event(s). The problem with catastrophic events is that the underlying probability distribution may not be well known, and therefore the magnitude of the financial liability is unknown. The insurance industry has traditionally handled this problem through reinsurance: insurance for insurance companies. This enables a spreading of the risks to other parties willing to accept those risks. The financial consequences of natural disasters in recent decades have led to changes in the disaster insurance business. The companies have responded by reassessing their decision to supply catastrophic insurance and reevaluating the adequacy of the level of premiums. Changes in the law, at both the state and federal level, have been enacted and the role of government has increased.

Innovations in financial markets also offer new possibilities affecting the supply and price of catastrophic insurance. Due to the need for insurance companies to reduce their risk exposure, reinsurance contracts have long been issued. There are two basic types of reinsurance: facultative and treaty. In the case of facultative reinsurance, each risk is underwritten separately and therefore the reinsurer can accept or reject each individual risk. The reinsurer is under no obligation to accept the particular risk offered and the insurer is under no obligation to cede the particular risk. For treaty reinsurance, the terms and conditions are pre-negotiated by the insurer and reinsurers and the insurer must cede all risk falling within the terms and conditions of the treaty. The reinsurer must accept all risk within the terms and conditions of the treaty. (See Guy Carpenter and Co.).

Though financial risk is often viewed in terms of "fear of the big one," the accumulation of so-called small catastrophic events can cause large collective insured losses. Problems for the industry began in the mid-1980s when strong profitability attracted many new players, capital and capacity in reinsurance. In 1992, two major hurricanes (Andrew and Iniki) contributed about $\$ 18$ of the $\$ 23$ billion in catastrophe losses that year. Soft conditions and fierce competition developed after 1992, leading to yet another insurance cycle. In addition to concerns about weather related disasters, there is also the reinsurers' exposure to environmental liabilities, as was the case with the Gulf oil spill in 2010. Since 1987, a downward trend in the ratings of the top 50 reinsurance companies has included a reduction in the number with superior, $\mathrm{A}++$ and $\mathrm{A}+$, ratings. Despite problems in the industry, the pre-tax five-year return on premiums for the top 5-10 companies remains approximately $15-20 \%$, though this performance overshadows that of the remaining firms who collectively returned only $3-5 \%$. The top 20 individual reinsurers have $79 \%$ of the premium revenue and $87 \%$ of the surplus for the reinsurance industry.

\section{II.3 The Insurance Cycle and Katrina}

Worldwide from 2000 to 2008 alone, overall weather related losses totaled more than $\$ 750$ billion, while insured losses came to around $\$ 280$ billion (Booth 2010). For the decade 2000-2009, insured losses in the U.S. amounted to more than $\$ 190$ billion (Benyon 2010). Of this, about $\$ 20$ billion was a result of September 11th but just over one-third of the insured losses occurred in 2005 as a result the hurricanes Katrina, Rita, and Wilma. Total losses were estimated to be over $\$ 100$ billion with $\$ 60$ billion insured losses (Benyon 2010). Hurricanes Katrina, Rita and Wilma swept through the Caribbean, the Gulf of Mexico and the southern states of the U.S. in 2005, leaving a trail of mass destruction (Booth 2010).

Katrina was the most destructive Atlantic hurricane ever. There were nearly two thousand lives lost on the Gulf Coast and an enormous impact on the New Orleans area catastrophe insurance industry (Benyon 2010). 
Those who benefitted from the huge losses of the catastrophe insurance industry were the startup insurers and reinsurers who entered the market beginning in January 2006. The new firms including Validus, Flagstone Re, Lancashire, Ariel Re and Harbor Point (now Alterra Capital, since merging with Max Capital) were flush with hedge fund capital and stoked a competitive market for catastrophe insurance. The reason for this was that rates increased and terms of the insurance contract were stiffened. As Benyon notes, these new firms took advantage of new investment vehicles (termed sidecars) as a convenient way to invest in the catastrophic insurance industry but with a limited lifespan so that investors could take advantage of short-term spikes in rates and then exit easily. The most noteworthy newcomers to the industry came in two waves of start-ups on Bermuda which has firmly established itself as a preeminent insurance center. Established firms, especially from Lloyd's, rushed to set up subsidiaries on the island and sidecars emerged as a way to increase capacity for existing firms (Booth 2010).

At the same time, these new firms were also held to higher standards by the rating agencies which demanded tougher capital requirements-new startups needed at least one billion dollars in capital. All firms increased their use of catastrophic risk modeling techniques after Katrina. Though some feel that there are too many firms in the market, mergers and acquisitions have been rare since 2005 (Benyon 2010). According to Bradford (2010), insurers were caught off guard by the storm and suffered unexpectedly heavy losses that forced them to rethink the way they underwrite hurricane risks. One result was for insurers to offer far less windstorm coverage for hurricane risks, even as pricing for limits that were available stabilized. Bradford (2010) states:

Prior to Katrina, there were no limitations on windstorm coverage. It was common to have a $\$ 2$ billion limit on fire, which included $\$ 2$ billion for windstorm. Today, it is much more common to see $\$ 100$ million or $\$ 200$ million for windstorm.

Though windstorm prices moved up, they softened in 2010 even with the forecast for an active hurricane season. The catastrophe insurance industry also suffered a public relations disaster in the wind versus water debate over Katrina (Mills 2010). Because of the National Flood Insurance Program, basic coverage up to $\$ 250,000$ is very affordable and covers what is totally excluded from a standard homeowners policy.

In the five years since Katrina, Congress has failed to make any significant reforms in the National Flood Insurance Program, which has stayed unchanged as lawmakers spur it along with occasional short-term extensions (Hamilton 2010). The "wind vs. water" debate is less clear in light of a ruling by the Mississippi Supreme Court, in regard to damages from Hurricane Katrina, that wind damage from hurricanes might still be covered even if excluded flood damage caused by a wind-blown storm surge was also present (Friedman 2009).

Changes that impacted the catastrophe insurance industry in the period 2005-2010 can be summarized as:

- An unusually large catastrophic event;

- Large payouts by the catastrophic insurance industry;

- A reduction in capacity in the affected area and an increase in premiums;

- Calls for regulatory changes at the state and federal level;

- Litigation in the courts;

- Introduction of new firms into the industry and a consequent increase in capacity;

- Premium pricing begins to soften;

- The stage is set for the next catastrophic event. 


\section{II.4 A Theoretical Explanation of the Cycle in Efficient Insurance Markets}

The empirical presence of this cycle appears to compromise the accuracy of traditional financial models of insurance market equilibrium. Such an equilibrium, in an economy with complete capital markets, competitive commodity markets and uniform information about potential future losses, requires that, conditional on such information, premia on new coverage exhibit no forecastable patterns over time, deviating only randomly from the expectations of market participants and, consequently, equal or exceed the discounted value of the expected costs of providing such coverage at the time coverage is purchased (Myers 1987). Intertemporal cycles in the availability of property-liability coverage and in the corresponding pricing of such coverage appear to be evidence against the premises of these models. Assertions of the rationing of coverage, periodic market exit, litigation over delayed compensation and inequitable pricing in these episodes of excessive volatility have, moreover, caused many policymakers, academics and members of the business press to interpret such volatility as evidence of the presence of more fundamental market failures. Such an interpretation, in turn, suggests that appropriate public regulation of insurance markets may increase their economic efficiency as well as the welfare of members of at-risk cohorts or communities.

Consider, more specifically, a representative insurer assessing the equity value of new underwriting of property-liability coverage in a specific market in which potential policyholders are exposed to catastrophic losses from random but actuarially predictable sources of risk. ${ }^{2}$

Management and shareholders of insurance firms perceive that the value of aggregate policy coverage from new underwriting represents a complex (financial) option. The current equity value (payoff) from new underwriting, consequently, is a convex function of the degree of exposure risk in this coverage. Increasing exposure risk through new underwriting, in the presence of such convexity, increases the equity value of the insurance firm and makes the decision to underwrite new lines more attractive. This is strictly true under the alternative assumptions that the structure of the insurance market is competitive or, should this market be monopolistically competitive, that the franchise value of participating insurance firms is sufficiently small. Note also that, should the parameters of the actuarial distribution of loss be currently only imperfectly known, exposure risk exhibiting a negative net current value in conventional terms can actually have a positive current value, owing to the inclusion of the "shadow" value of obtaining additional information about the actual loss distribution generated by underwriting, making such underwriting even more attractive to shareholders. This will be true, of course, even if the decision to underwrite, as an irreversible investment in information, turn out to be bad, ex post, for firm value.

Regulatory risk, in contrast, reduces the value of new underwriting to firm shareholders. Government actions intended to stabilize the supply and pricing of insurance coverage, including limits on the pricing of exposure risk, rate roll backs, coverage restrictions, mandated pooling of lines, regulatory barriers to exit and other measures, increases the current expected costs of new coverage and, consequently, reduce those gains to shareholders created by increasing the exposure risk of the firm. It may be rational, should regulatory risk become sufficiently large, for firms to cut back or refuse to underwrite new coverage, even when that coverage has a positive expected net present value, because both the exposure to future loss and the value of premia may change in unanticipated ways, whether or not underwriting is done.

Allowing for variation in the competitive structure of the specified property-liability insurance market, we model market equilibrium and the behavior of participating firms and regulators in the context of a stochastic continuous-time differential game. The underlying economy in this game exhibits the standard assumptions used in asset pricing, including the presence of complete capital markets and satisfaction of the condition of no-arbitrage in the pricing of insurance and other financial instruments. ${ }^{3}$ The simultaneous effects of exposure

2 Although automobile and employee compensation remain the largest lines in the United States, residential and commercial property lines for large damages from various forms of natural and man-made catastrophes have dramatically increased as a proportion of all property-liability insurance in the United States (Fitzpatrick (2004), Leng and Meier (2006) are the most publicized sources of loss and industry liability. Since losses from these sources constitute the major concern of both policymakers and local and national electorates, in what follows we use the term "catastrophic" to describe coverage and contracts in property-liability insurance markets. This expository convenience does not, however, compromise the generality of our results for such markets nor the implications of these results for public policy.

3 General applications of this type of game to asset markets can be found in Fine and Li (1988) and Dutta and Rustichini 
risk and regulatory risk are illustrated through examination of the best-reply strategies respectively adopted by the representative insurance firm and representative regulator. Based on these strategies, the fundamental value equation for the representative insurance firm is derived and a (subgame perfect) market equilibrium is obtained. In this equilibrium, we show that intervention by regulators, through a transaction rule designed to mitigate excess insurance demand, can actually cause insurance underwriting to exhibit an arbitrarily large degree of intertemporal volatility and, under certain parametric conditions, equilibrium values of insurance pricing and coverage will exhibit a limit cycle of the type actually observed in actual property-liability insurance markets. We now turn in the next section to the formalization of a model to explain these events.

\section{A Model of the Property-Liability Insurance Market}

Consider the decision to underwrite a line of business. The insurer will receive, at the time of this decision, a premium net of commissions and sales expenses, $p$, and he will pay random losses and adjustment expenses, $L$, on this line. The ratio of these values is the random losses to premium ratio, $l$, which has the expected value $\bar{l}$, where

$$
E\left(\frac{L}{p}\right)=\bar{l} .
$$

If there was no uncertainty over the losses, the value of one dollar of underwriting would just be

$$
V=\max \left[1-\bar{l} e^{-r t}, 0\right]
$$

where $r$ is the riskless rate.

Uncertainty over losses is introduced by specifying the loss per dollar of underwriting to follow a diffusion process:

$$
d l=\alpha(l) d t+f(p, L) d z,
$$

where $d z(t)$ is white noise and where the derivatives of $f(\cdot)$ satisfy the restrictions $f_{L}>0, f_{p} \geq 0, f_{p p} \leq 0$, and where we restrict $f(\cdot)$ to satisfy $\lim _{l \rightarrow 0} \operatorname{var}(d l)=0$.

This says that the expected losses decline with the amount of underwriting, but the losses also change stochastically.

The restrictions on the function $f(\cdot)$ in equation (1) are imposed because actuarial evidence indicates that the variance of the losses are bounded, and that the variance of the losses goes to zero, as the expected losses go to zero. Since neither the underwriting losses or regulatory actions are correlated with the market, the risk free rate can be used as the appropriate discount rate. ${ }^{4}$ The value of one dollar of underwriting is now:

$$
V(l)=\max E\left[\left(1-\int_{0}^{T} l(s) e^{-r s} d s\right), 0\right],
$$

where $T$ is the duration of the contract. By restricting $V(\cdot)$ to be homogeneous, $f(\cdot)$ can be written as ${ }^{5}$

$$
\begin{aligned}
f(p, L) & =f(l) \\
& =\eta\left(\frac{L}{p}\right)^{(1 / 2-\gamma)} \\
& =\eta l^{(1 / 2-\gamma)}
\end{aligned}
$$

(1991). Analytical and numerical results for the specific case of debt markets appear in Heaney and Jones (1990) and in Jones and Nickerson (1994).

4 Note that we are assuming an economy in which the assumptions requisite for the CAPM are satisfied.

5 See Karlin and Taylor (1981). 
where $\eta$ and $\gamma$ are constants to be determined by initial conditions. By restricting $\gamma$ to $0 \leq \gamma<1 / 2$, the condition $V_{l}=\partial V / \partial l<0$ is insured.

The limiting cases of $\gamma=0$ and $\gamma=1 / 2$ correspond to the two types of uncertainty with which we are concerned. When $\gamma=1 / 2$, the variance of $l$ changes only if the firm is underwriting, and the variance of $d l / l$ will be proportional to $1 / l$. This case corresponds to uncertainty about losses. When $\gamma=0$, the variance of $d l / l$ is constant. This case corresponds to regulatory risk.

Both types of uncertainty can be modeled by combining the two alternative functional forms in a single equation with two correlated sources of noise:

$$
d l=\alpha d t+\eta_{1} d z_{1}+\eta_{2} \lambda d z_{2}
$$

where $d z_{1}$ and $d z_{2}$ are Gaussian, $\rho$ is the correlation between these terms, and, since the ratio of losses to premiums can not take on negative values, it is useful to implement the change of variable $\lambda=\sqrt{l}$. This stochastic processes is a form of the general Ornstein-Uhlenbeck process and represents the stochastic evolution of the ratio of losses to premium. ${ }^{6}$

\section{The Valuation Equation and A General Form of the Underwriting Cycle}

The value of underwriting may be obtained from solving the fundamental valuation equation for this asset. By Ito's Lemma, the instantaneous change in this value must satisfy the partial differential equation,

$$
\begin{aligned}
d V & =V_{l} d l+\left(\frac{1}{2}\right) V_{l l} d l^{2} \\
& =\alpha V_{l} d t+\eta_{1} V_{l} d z_{1}+\eta_{2} \lambda V_{l} d z_{2}+\left(\eta_{1}^{2}+2 \rho \lambda \eta_{1} \eta_{2}+\eta_{2}^{2} \lambda^{2}\right) d t
\end{aligned}
$$

Assuming complete capital markets, the price of asset risk, $\phi$, is common across all traded assets. We can then derive a valuation equation for underwriting by requiring the riskless return on borrowing of a magnitude equal to the implicit value of underwriting, $r V d t$, be equal to the expected capital gain from a riskless portfolio composed of underwriting and a market asset. Adjusting the conditional mean of the diffusion process governing the evolution of the value of underwriting in (3) by the usual Kac-Feynman procedure, the valution or Bellman equation describing the value of underwriting is:

$$
\begin{aligned}
r V d t & =E(d V) \\
& =\theta V_{l l}+(\alpha-\phi) V_{l},
\end{aligned}
$$

where

$$
\theta=\eta_{1}^{2}+2 \rho \lambda \eta_{1} \eta_{2}+\eta_{2}^{2} \lambda^{2}
$$

The valuation equation can, consequently, be re-written as the ordinary autonomous differential equation,

$$
0=\theta V_{l l}+(\alpha-\phi) V_{l}-r V
$$

in which the right side does not include the independent variable for time. Equation (7) is the autonomous valuation equation for the value of underwriting.

\footnotetext{
6 The Ornstein-Uhlenbeck process is discussed more extensively in Cox, Ingersoll, and Ross (1985), among other sources.
} 
The space of solutions for the valuation equation is circumscribed by the appropriate boundary conditions. ${ }^{7}$ Using these boundary conditions, a general implicit solution to the valuation equation in (6) can be expressed as:

$$
v(l)=c_{2}+\int\left\{c_{1} e^{\zeta}+2 e^{\zeta} \int_{0}^{l}\left(\frac{e^{\zeta}}{\theta} d x\right)\right\} d l,
$$

where

$$
\begin{aligned}
\zeta & =2 a_{1} \tan ^{-1}\left(a_{2}\right), \\
a_{1} & =\left(\eta_{1}^{2}-\rho^{2} \eta_{1}^{2} \eta_{2}\right)^{-(1 / 2)} \\
a_{2} & =\frac{\rho \eta_{1}+l \eta_{2}}{\sqrt{\eta_{1}^{2}-\rho^{2} \eta_{2}}}
\end{aligned}
$$

\section{An Example of the Underwriting Cycle}

Assuming the value of $\eta_{2}$ in equation (8) is set to be of arbitrarily small exponential order, and denoting $\delta$ $=\eta_{1} \sqrt{2}$, the solution to the valuation equation with these initial values is: ${ }^{8}$

$$
V(\lambda)=\left(\frac{d}{a-b}\right)\left(e^{a l}-e^{b l}\right),
$$

where

$$
\begin{aligned}
& a=\frac{1-2 \delta^{2} \rho-\sqrt{\left(1+2 \rho \delta^{2}\right)-4 \delta(1+\delta \rho) r}}{2 \delta(1+\delta \rho)}, \\
& b=\frac{1-2 \delta^{2} \rho+\sqrt{\left(1+2 \rho \delta^{2}\right)-4 \delta(1+\delta \rho) r}}{2 \delta(1+\delta \rho)},
\end{aligned}
$$

This solution can be more succinctly expressed as:

$$
V(\lambda)=\left(\frac{d}{a-b}\right)\left[e^{1-2 \rho \delta^{2}}\left(e^{\alpha l}-e^{-\alpha l}\right)\right]^{\frac{1}{2 \delta(1+\rho \delta)}},
$$

where

$$
\begin{aligned}
\alpha & =\sqrt{\Delta} \\
\Delta & =\left(1+2 \rho \delta^{2}\right)-4 \delta(1+\rho \delta) r .
\end{aligned}
$$

In analyzing this solution for firm value $V(\lambda)$, two cases must be examined. The first case, in which the discriminant, $\Delta$, satisfies

$$
1+2 \delta^{2} \rho>4 \delta(1+\delta \rho) r
$$

7 These boundary conditions,

$$
\begin{aligned}
\lim _{\lambda \rightarrow 0} V(\lambda) & \rightarrow 0 \\
\lim _{\lambda \rightarrow 0} V^{\prime}(\lambda) & \rightarrow 1 \\
\lim _{\lambda \rightarrow \infty} V(\lambda) & \rightarrow 0 .
\end{aligned}
$$

can be respectively interpreted as follows. Since for a firm to have no losses, a firm must do no underwriting, the first condition statement says that such a firm will have no value. The second condition states that the marginal loss rate per dollar of premium is one with the first dollar of premium written. The third says that an unlimited loss rate produce an insurer with no equity value.

8 That is, choosing $\eta_{2}$ to satisfy $\eta_{2}^{\zeta} \approx 0$ for any $\zeta>1$. 
yields real roots and does not produce cyclical behavior. The second case, in which

$$
1+2 \delta^{2} \rho<4 \delta(1+\delta \rho) r,
$$

generates complex (sinusoidal) roots. This second case yields the following expression for underwriting value:

$$
\begin{aligned}
V(l) & =\left(\frac{d}{a-b}\right)\left[e^{1-2 \rho \delta^{2}}\left(e^{i z l}-e^{-i z l}\right)\right]^{\frac{1}{2 \delta(1+\rho \delta)}}, \\
& =\left(\frac{d}{a-b}\right)\left[e^{\left(1-2 \rho \delta^{2}\right)} \sin (z l)\right]^{\frac{1}{2 \delta(1+\rho \delta)}} .
\end{aligned}
$$

This solution will be harmonic if $\Delta<0$. This will, in general, be the case, for plausible parameter values. In particular, the following restriction must be satisfied on the parameters $\rho$ and $\delta$ :

$$
\left(\frac{1}{2 \delta^{2}}\right)\left(\frac{1-4 r \delta}{1-2 r}\right)>\rho,
$$

A sufficient conditon for satisfaction of this condition is:

$$
\rho<\frac{r^{2}}{r-(1 / 2)} .
$$

This range of values for $\rho$ is consistent with a negative relationship between the regulatory and underwriting stochastic process. This is consistent with the observation that the industry is apt get regulatory relief after a period of poor underwriting results. The interest rate environment of this range, with annual rates less than fifty percent, is consistent with that experienced in most industrialized economies.

The general solution to the differential equation will be a series of functions having the form of the particular solution. Thus, uncertainty about losses, and uncertainty about the actions of the regulator, are sufficient to generate an underwriting cycle.

\section{Insurance Market Efficiency and the Role of Public Policy}

There are three basic and interrelated questions regarding the efficiency of property-liability insurance markets: (1) what volume of coverage will occur in market equilibrium; (2) what will determine the equilibrium price of such coverage; and (3) what is the potential role, if any, of government regulation in insurance markets. The first question is whether catastrophe insurance will be supplied. For the entire property/casualty insurance business for 1995, $\$ 241$ billion in insurance premiums were collected. Of this, 3.35, or $\$ 7.9$ billion was collected for fire, earthquake, and allied lines. For homeowners with multiple peril, the figures are $8.9 \%$ and $\$ 21.5$ billion. The largest category is for private passenger automobiles at $38.6 \%$ and $\$ 93.4$ billion. (See C. England study) The surplus available to the industry as a whole for catastrophic events is about $\$ 200$ billion. For the reinsurance industry, net premiums written in 1995 were about $\$ 16$ billion with a policyholders surplus of about $\$ 40$ billion.

When there is a large disaster, companies reassess the likelihood of future payouts. This can be a sticky problem since unexpectedly large payouts which threaten solvency basically mean that the insurance company did a bad job of assessing risks and setting premiums. The customers, and state officials and regulators, view the situation as one where the companies are only there as long as premiums exceed payouts, and once there are large losses, the companies refuse to reinsure. Even with unexpectedly large losses, if the insurance companies still believe their risk assessments, there is not necessarily a reason to pull out of the disaster area. Simply put, the chances of back-to-back Hurricane Andrews are probably very low.

However, a low probability event may have a large payout which would cause the company to fail. As a result of Hurricane Andrew, eleven companies failed and Allstate paid out more in Andrew-related claims 
by homeowners than its total profits from the Florida homeowners market in more than fifty years of doing business there (cited in England, p. 19). A California Department of Insurance survey found rising rates and an availability crunch for homeowner insurance as a result of the Northridge, California earthquake. A survey taken in 1995 found that $93 \%$ of the California insurance market is not writing new policies, while tougher limits are being imposed on policies. Only $7 \%$ of the state home owners market is writing unrestricted policies (see article in Insurance Industry International, n. 37, p. 2).

Pricing is very important, and a recent insurance industry analyst accused State Farm, Allstate, and other American providers of homeowners insurance, of creating their own catastrophe problems by under pricing policies that are too rich with benefits. Specifically, the companies are providing guaranteed replacement cost policies plus wear and tear. Since this shift, beginning in the 1980s, the analyst claims, homeowner premiums fell as much as $40 \%$ from $\$ 350$ per $\$ 100,000$ of property exposure in 1984 to only $\$ 210$ per $\$ 100,000$ in 1995 . What started out as bells and whistles added to policies as marketing ploys, has turned into a billion-dollar headache. The dilemma is that with the disasters, and with state regulators looking closely at them, it will be more difficult to raise premiums. Hence, even if the private sector provides catastrophe insurance, mispricing may cause problems in the long run. Competitive pressures to generate more policies can lead to this underpricing since the companies show increased profitability until disasters hit. (See Journal of Commerce article, v410, no28, p. 8a) Finally, what is the proper role of government in the event that insurance losses threaten the solvency of the companies? If participants believe that the government would bail out the insurance companies under such circumstances, this creates a moral hazard problem typically described as "too big to fail." Under those circumstances, market distortions will occur.

\section{Concluding Remarks}

This paper employs a stochastic differential game to generate a cycle in the loss ratio of a representative insurance firm when that firm is simultaneously exposed to uncertainty about policy losses and uncertainty about the actions of regulators. The model includes a role for the value of the information that comes from underwriting experience, which decreases uncertainty over profitability, and uncertainty over regulatory policy, which increases such uncertainty. The perfect Nash equilibrium in this game generates, under plausible parametric conditions, a cyclical value of insurance underwriting, even when capital markets are complete with respect to the underlying source of uncertainty. Such cyclicity implies that a potential cause of the underwriting cycle in the propertyliability insurance industry may be the very regulatory policy which is employed in the hopes of dampening such cycles. 


\section{References}

Baker, T. (2010) The Shifting Terrain of Risk and Uncertainty on the Liability Insurance Field, U of Penn, Institute for Law and Economics Research Paper, No. 10-32.

Barnes, S., and Terrell, D. (2009) The Impact of the Labor Market on Health Insurance, Journal of Labor Research, 30(4), 328-339. doi:10.1007/s12122-009-9069-2

Benyon, D. (2010) The Class of 2005 Reinsurers five years on, Reactions, 288.

Berger, L. A. (1988) A Model of the Underwriting Cycle in the Property-Liability Insurance Industry, Journal of Risk and Insurance, 55(2), 298-306.

Booth, G. (2010) A Decade of Disaster, Reactions, 18-21.

Bradford, M. (2010) Katrina Changed How Insurers Underwrite Risks, Business Insurance, 44(34), 13.

Chen, R., Wong, K., and Lee, H. (1999) Underwriting Cycles in Asia. Journal of Risk and Insurance, 29-47.

Choi, J., and Powers, M. (2002) Global Risk Management: Financial, Operational, and Insurance Strategies, International Finance Review, 3(1), 66-78.

Choi, S., Hardigree, D. and Thistle, P. D. (2002) "The Property/Liability Insurance Cycle: A Comparison of Alternative Models," Southern Economic Journal, 68 (3), 530-548.

Cornejo, R. (2010) Claims Redux, Best's Review, 111(2), 24-25.

Cornejo, R. (2010) The Tide Turned, Best's Review, 111(2), 30-31.

Cox, J., Ingersoll, R. and S. Ross (1985) A Theory of the Term Structure of Interest Rates, Econometrica, 53, $385-408$.

Cross, M. L., and Simmons, L. F. (1988) The Underwriting Cycle and the Risk Manager-Authors' Reply. Journal of Risk and Insurance, 55(3), 561-562.

Cummins, J., and Derrig, R. (1991) Managing the Insolvency Risk of Insurance Companies, Proceedings of the Second International Conference on Insurance Solvency, Huebner International Series on Risk, Insurance, and Economic Security.

Cummins, J., and Outreville, J. (1987) An International Analysis of Underwriting Cycles in Property-Liability Insurance. Journal of Risk and Insurance, 54(2), 246-262.

Cummins, J., and Outreville, J. (1992) An International Analysis of Underwriting Cycles in Property-Liability Insurance. In G. Dionne, S. E. Harrington (Eds.) , Foundations of Insurance Economics: Readings in Economics and F,inance Huebner International Series on Risk, Insurance, and Economic Security.

Cummins, J., and Weiss, M. A. (2009) Convergence of Insurance and Financial Markets: Hybrid and Securitized Risk-Transfer Solutions. Journal of Risk and Insurance, 76(3), 493-545.

Dicks, D. (2009) A Theory of Capital-Driven Cycles in Insurance,University of North Carolina, Kenan-Flagler Working Paper.

Dionne, G. (2000) Handbook of insurance, Huebner International Series on Risk, Insurance, and Economic Security.

Dutta, P. and Rustichini, A. (1993) A Theory of Stopping Time Games with Applications to Product Innovations and Asset Sales, Economic Theory, 3(4), 743-763.

Embrechts, P. (2009) Stochastic Processes in Insurance and Finance, it Department of Mathematics, Eidgenssische Technische Hochschule Working Paper.

England, C. (1995) The Business of Insurance, American Enterprise Institute, Washington, D.C. 
Fitzpatrick, S. (2004) Fear is the Key: A Behavioral Guide to Underwriting Cycles, Connecticut Insurance Law Journal, 10(2), pp. 255-275.

Friedman, S. (2009) Mississippi Hurricane Katrina Ruling Creates Coverage Uncertainty On Wind vs. Water. National Underwriter, Oct, 8.

Fung, H. (1998) Underwriting Cycles in Property and Liability Insurance: An Empirical Analysis of Industry and By-Line Data, Journal of Risk and Insurance, 65(4), 539-561.

Gay, R. (2004) Pricing Risk When Distributions are Fat Tailed, Journal of Applied Probability, 41(A), 157-175.

Goch, L. (2010) Five Years Later, Best's Review, 111(2), 1.

Goovaerts, M. J., De Vylder, F. F., and Kaas, R. R. (1992) A Stochastic Approach to Insurance Cycles, Insurance: Mathematics and Economics, 11(2), 97-107.

Grace, M. and J. Hotchkiss (1995) External Impacts on the Property-Liability Insurance Cycle, Journal of Risk and Insurance, 62( 4), 121-145.

Green, M. (2010) An Alternate Route, Best's Review, 111(2), 38-39.

Green, M. (2010) The Class of 2005 Grows Up, Best's Review, 111(2), 40-41.

Gron, A. (1994) Capacity Constraints and Cycles in Property-Casualty Insurance Markets, RAND Journal of Economics, 25(1), 110-127.

Guy Carpenter and Co. (1996) Reinsurance Overview, at http://www.Guycarp.com/course.htm.

Hamilton, J. A. (2010) Five Years and Zero Progress, Best's Review, 111(2), 36-37.

Harrington, S. E., and Niehaus, G. (2000) Volatility and Underwriting Cycles, in G. Dionne (ed.) , Handbook of insurance,Huebner International Series on Risk, Insurance and Economic Security, pp. 657-686.

Heaney, R. and Jones, R. (1990) The Timing of Investment, Economics Department, Simon Fraser University Working Paper.

Hemenway, C. (2010) Open for Business, Best's Review, 111(2), 32-33.

Hemenway, C. (2010) Setting an Example, Best's Review, 111(2), 34-35.

Higgins, M. L., and Thistle, P. D. (2000) Capacity Constraints and the Dynamics of Underwriting Profits, Economic Inquiry, 38(3), 442-457.

Huang, C. and Li, L. (1986) Continuous-Time Stopping Games, Sloan Scool of Management, M.I.T. Working Paper.

Jablonowski, M. (1988) The Underwriting Cycle and the Risk Manager: Comment, Journal of Risk and Insurance, 55(3), 559-560.

Jones, R. and Nickerson, D. (2004) Mortgage Contracts, Strategic Options and Stochastic Collateral, Journal of Real Estate Finance and Economics, 24(1), 35-58.

Journal of Commerce (1996) Rates for a Disaster for Home Insurers, 410(28), 13.

Karlin, S., and Taylor, H. (1981) A Second Course in Stochastic Processes, New York: Academic Press.

Kerney, G. (2009) The New Era of Megacatastrophes, Risk Management, 56(3), 68-73.

Lai, G., R. Witt, H. Fung, R. MacMinn and P. Brockett (2000) Great (and not so Great) Expectattions: An Endogenous Economic Explication of Insurance Cycles and Liability Crises, Journal of Risk and Insurance, 67(4), 617-652.

Lamm-Tennant, J. and M. Weiss (1997) International Insurance Cycles: Rational Expectations/Institutional Intervention, Journal of Risk and Insurance, 64(3), 212-231.

Leng, C. and U. Meier (2006) Analysis of Multinational Underwriting Cycles in Property-Liability Insurance, Temple University, Fox Business School, Working Paper. 
Liebenberg, A. P., and Kamerschen, D. R. (2008) Structure, Conduct and Performance Analysis of the South African Auto Insurance Market: 1980-2000, South African Journal of Economics, 76(2), 228-238.

McKenzie, R., and Levendis, J. (2010) Flood Hazards and Urban Housing Markets: The Effects of Katrina on New Orleans, Journal of Real Estate Finance and Economics, 40(1), 62-76.

Meier, U. (2006) Multi-National Underwriting Cycles in Property-Liability Insurance, Part I: Some Theory and Empirical Results, Journal of Risk Finance, 7-64

Melnikov, A. (2004) Risk Analysis in Finance and Insurance, CRC Monographs in Pure and Applied Mathematics, Chapman and Hall (London.)

Michel-Kerjan, E. (2010) Catastrophe Economics: The National Flood Insurance Program. Journal of Economic Perspectives, 24(4), 165-186.

Mills, H. (2010) A Shining Moment or Another Shiner?. Best's Review, 111(4), 71.

Niehaus, G. (2008) Insurance and Risk Management. Elgar Reference Collection in Business Economics, vol. 7.

Seog, S. (2008) Informational Cascades in the Insurance Market, Journal of Risk and Insurance, 75(1), 145-165.

Shuford, H. (2004) Understanding Cycles and Shocks in the Property and Casualty Insurance Industry, Business Economics, 39(3), 38-49.

Simmons, L. F., and Cross, M. L. (1986) The Underwriting Cycle and the Risk Manager, Journal of Risk and Insurance, 53(1), 155-163.

Solomon, O., and Pricina, C. (2008) Time Delays and the Underwriting Cycle. Romanian Economic and Business Review, 3(4), 35-43.

Taylor, G. (1991) An Analysis of Underwriting Cycles and Their Effects on Insurance Solvency, in J. Cummins and R. A. Derrig (eds.) , Managing the Insolvency Risk of Insurance Companies: Proceedings of the Second International Conference on Insurance Solvency,Huebner International Series on Risk, Insurance, and Economic Security, 3-76.

Trufin, J., H. Albrecher and M. Denuit, (2009) Impact of Underwriting Cycles on the Solvency of an Insurance Company, North American Actuarial Journal, 13(1) 373 -385.

Winter, R. (1991) The Liability Insurance Market, Journal of Economic Perspectives, 5(3), 115-136.

Winter, R. (1994) The Dynamics of Competitive Insurance Markets, Journal of Financial Intermediation, 3(4), 289-301. 